\title{
INFLUÊNCIA DA CONCENTRAÇÃO DE CARREADORES NAS PROPRIEDADES FÍSICAS DE EXTRATO DE BETERRABA MICROENCAPSULADO
}

\author{
L. A. C. ZUANON ${ }^{1 *}$, V. R. N. TELIS ${ }^{1}$ \\ ${ }^{1}$ Universidade Estadual Paulista, Departamento de Engenharia e Tecnologia de Alimentos \\ e-mail: larizuanon@gmail.com
}

\begin{abstract}
RESUMO
O presente trabalho teve como objetivo a obtenção de microcápsulas de betalaínas obtidas do extrato de beterraba pelo processo de spray drying. Foram produzidas partículas utilizando diferentes tipos de agentes carreadores: maltodextrina 10DE (Md) e amido de milho modificado (Am) adicionadas do extrato de beterraba, resultando em um grupo de quatro amostras: Am80Md20[15], Am80Md20[35], Am50Md50[15], Am50Md50[35], que foram analisadas quanto ao tamanho das partículas, aos parâmetros de cor $(L, C$ e $h$ ), além de rendimento e umidade. O rendimento do processo variou entre 51 e $82 \%$ enquanto os valores de umidade foram inferiores a $2 \%$. A concentração e a proporção Am:Md causaram um efeito negativo no valores de $C$, ou seja, quanto maior a concentração e a proporção $\mathrm{Am}$ :Md, menor o valor $C$ obtido. Em relação ao parâmetro $L$, os valores apresentaram diferença significativa entre as amostras, o que não foi observado para $h$. As amostras com maior concentração total de carreadores resultaram em partículas maiores, o que está relacionado ao aumento da viscosidade da mistura a ser seca.
\end{abstract}

\section{INTRODUÇÃO}

Nos últimos anos, o interesse em corantes naturais aumentou consideravelmente, principalmente pela toxicidade quase nula e por serem ecologicamente corretos. Corantes naturais são antioxidantes nutricionais e sua presença na dieta pode reduzir o risco de doenças cardiovasculares, câncer e doenças associadas ao envelhecimento.

Os pigmentos mais importantes $\mathrm{e}$ abundantes na beterraba são as betalaínas, que são quimicamente definidos como derivados de ácidos betalâmico. As betalaínas conferem uma cor vermelha desejável em alimentos e têm inúmeras aplicações na indústria, como aditivos em gelatinas, sobremesas, doces, alimentos assados, etc. (CHETHANA; CHETAN; RAGHAVARAO, 2006).

A microencapsulação por atomização é uma solução econômica e um método muito utilizado para a preservação de corantes naturais por aprisionamento dos ingredientes em um material de revestimento. (PITALUA et al., 2010). É de grande importância para a indústria otimizar este processo de secagem, afim de obter produtos com melhores características sensoriais e nutricionais, bem como aumentar o rendimento. Uma alternativa para evitar os problemas de manipulação e processamento é adicionar agentes carreadores, que melhoram a estabilidade do material durante a secagem e o armazenamento, desempenhando ainda a função de agentes encapsulantes 
(BHANDARI et al., 1993; RIGHETTO; NETTO, 2005).

Considerando-se que a beterraba apresenta uma grande quantidade de betalaínas e consequentemente, uma elevada capacidade antioxidante, e levando-se em conta o fato de que as betalaínas são pigmentos instáveis, a microencapsulação do extrato de beterraba pode representar uma técnica promissora no sentido de aumentar a estabilidade desses pigmentos.

O presente trabalho teve como objetivo a obtenção de microcápsulas de betalaínas obtidas do extrato de beterraba pelo processo de spray drying, caracterizando-as segundo as propriedades de tamanho das partículas, parâmetros de cor, umidade e rendimento.

\section{MATERIAIS E MÉTODOS}

\subsection{Materiais}

Para a obtenção do extrato, que será o material ativo na encapsulação, foram utilizadas beterrabas (Beta vulgairs L.) adquiridas no mercado local de São José do Rio Preto. Os agentes encapsulantes utilizados foram amido de milho ceroso enzimaticamente modificado (Am) (Hi-Cap ${ }^{\mathrm{TM}}$ 100, National Starch, Brasil), maltodextrina DE $10 \quad(M d) \quad\left(M o r-R e x{ }^{\circledR} \quad 1910, \quad\right.$ Corn Products, Brasil)

\subsection{Métodos}

\subsubsection{Extrato de beterraba}

$\mathrm{O}$ extrato de beterraba foi obtido pela homogeneização de $50 \mathrm{~g}$ de beterraba (Beta vulgaris L.) com $100 \mathrm{~mL}$ de etanol 70\%. Esta dispersão foi armazenada a $10{ }^{\circ} \mathrm{C}$ durante 24 horas e então filtrada e evaporada sob vácuo até volume constante $\left(15^{\circ} \mathrm{Brix}\right)$ (CUCHINSK 2010).

\subsubsection{Obtenção das microcápsulas}

Foram realizados quatro ensaios de secagem em um mini spray dryer (B-290,
Büchi, Suíça) com fluxo de ar de $500 \mathrm{~L} / \mathrm{h}$, temperatura do ar de entrada de $180{ }^{\circ} \mathrm{C}$, e a alimentação de $5 \mathrm{~mL} / \mathrm{min}$. Vinte $\mathrm{mL}$ de extrato de beterraba foram adicionados a soluções de 15 e $35 \%$ (p / p) de sólidos totais, com proporções Am:Md de 20:80 e 50:50. As soluções foram homogeneizadas em Ultraturrax a $18.000 \mathrm{rpm} / 5 \mathrm{~min}$ e em seguida levadas para a atomização.

\subsubsection{Caracterização das microcápsulas}

\subsubsection{Umidade e rendimento}

A análise de umidade em base seca foi realizada pelo método gravimétrico em estufa a $105{ }^{\circ} \mathrm{C}$ por 6 horas (AOAC, 1995). O Rendimento foi obtido por diferença de massa, antes e após o processo de secagem.

\subsubsection{Medidas de cor}

A cor das amostras foi avaliada por medidas objetivas da cor em colorímetro (Chroma Meter CR-5, Konica Minolta, Japão). Nesse sistema, $L$ representa a claridade da cor e as variações de cor foram expressas pelo ângulo de tonalidade cromática (h) e pela saturação da cor (C) na caracterização das microcápsulas, conforme as equações (1) e (2):

$$
\begin{aligned}
& h=\operatorname{tg}^{-1}(\mathrm{~b} / \mathrm{a}) \\
& C=\left[\left(\mathrm{a}^{2}\right)+\left(\mathrm{b}^{2}\right)\right]^{1 / 2}
\end{aligned}
$$

\subsubsection{Diâmetro médio das partículas}

O diâmetro médio das partículas foi determinado utilizando um analisador de distribuição de tamanho de partícula por difração a laser (Partica - LA 950, Horiba, Japan).

\section{RESULTADOS E DISCUSSÃO}

3.1. Extrato de beterraba e microcápsulas obtidas 
O extrato obtido apresentou cor violeta escuro, característico da beterraba (Figura 1). A figura 2 apresenta a imagem das quatro amostras, após passarem pelo processo de atomização.

Figura 1 - Extrato alcoólico de beterraba.

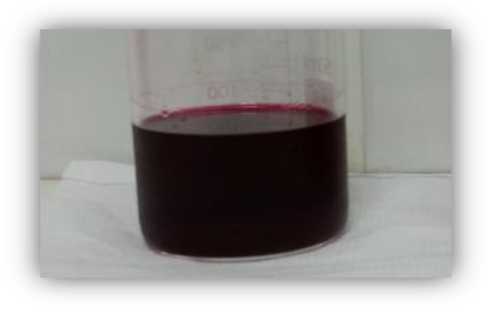

Figura 2 - Microcápsulas de betalaínas. Amostras ( a ) Am80Md20[15], ( b ) Am80Md20[35], ( c ) Am50Md50[15], ( d ) Am50Md50[35].

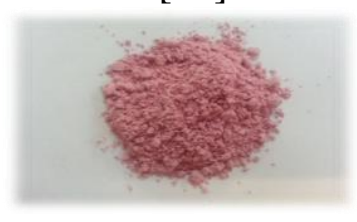

( a )

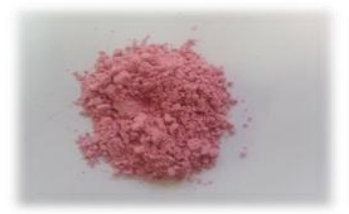

(c)

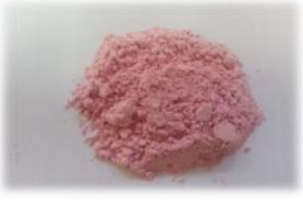

( b )

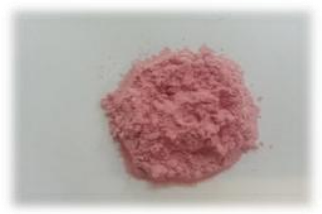

( d )

\subsection{Caracterização das partículas}

$\mathrm{Na}$ tabela 1 estão expressos os valores para umidade, rendimento do processo e diâmetro médio das partículas. Os resultados das análises de cor estão apresentados na tabela 2 .

Os valores de umidade variaram entre 0,39 e 1,74\%. Caliskan e Dirim (2013) encontraram valores de umidade semelhantes ao desse trabalho, não ultrapassando 2,94\%, na secagem de extrato de sumagre por spray dryer utilizando maltodextrina como agente carreador. Baixos valores de umidade estão relacionados à alta temperatura de secagem utilizadas neste estudo.

Tabela 1 - Umidade em base seca (Ubs), Rendimento do processo (R) e diâmetro médio das partículas (D).

\begin{tabular}{cccc}
\hline & $\begin{array}{c}\text { Ubs } \\
(\boldsymbol{\%})\end{array}$ & $\begin{array}{c}\text { R } \\
(\boldsymbol{\%})\end{array}$ & $\begin{array}{c}\mathbf{D} \\
(\boldsymbol{\mu m})\end{array}$ \\
\hline Am80Md20[15] & $1,74 \pm$ & 80,73 & $10,74 \pm$ \\
& 0,45 & & 0,10 \\
Am80Md20[35] & $0,59 \pm$ & 81,34 & $22,26 \pm$ \\
& 0,49 & & 0,24 \\
Am50Md50[15] & $1,70 \pm$ & 62,67 & $6,78 \pm$ \\
& 0,32 & & 0,08 \\
Am50Md50[35] & $0,39 \pm$ & 51,42 & $19,28 \pm$ \\
& 0,11 & & 0,27 \\
\hline
\end{tabular}

Os valores obtidos para rendimento variaram de 51,42 até $81,34 \%$. Estes resultados estão em concordância com os obtidos por Fazaeli et al. (2012) no estudo dos efeitos das condições de secagem por spray dyer nas propriedades físicas de suco de amora negra em pó, com maior rendimento de $82,0 \%$.

Tabela 2 - Parâmetros de cor

\begin{tabular}{cccc}
\hline & $\boldsymbol{L}$ & $\boldsymbol{C}$ & $\boldsymbol{h}$ \\
\hline Am80Md20[15] & $68,65 \pm$ & $21,07 \pm$ & $3,42 \pm$ \\
& 0,68 & 0,35 & 0,30 \\
Am80Md20[35] & $68,24 \pm$ & $22,98 \pm$ & $3,76 \pm$ \\
& 0,21 & 0,43 & 0,08 \\
Am50Md50[15] & $62,78 \pm$ & $29,00 \pm$ & $3,55 \pm$ \\
& 0,13 & 0,12 & 0,10 \\
Am50Md50[35] & $70,00 \pm$ & $23,01 \pm$ & $6,21 \pm$ \\
& 0,75 & 0,74 & 0,22 \\
\hline
\end{tabular}

As amostras apresentaram partículas com tamanho variando entre 6,78 e $22,26 \mu \mathrm{m}$ de diâmetro. Fernandes, Borges e Botrel (2014) encontraram partículas que não ultrapassaram 13,5 $\mu \mathrm{m}$ de diâmetro na microencapsulação de óleo essencial de alecrim em matrizes de goma arábica, amido, maltodextrina e inulina. $\mathrm{O}$ processo de microencapsulação por spray dryer é caracterizado pela formação de partículas pequenas. De acordo com a literatura, o 
diâmetro dessas partículas depende do método de atomização utilizado, das propriedades do material, da concentração e da viscosidade do material encapsulado e das condições de secagem (JAFARI; ASSADPOOR; BHANDARI, 2008).

A concentração e a proporção Am:Md causaram um efeito positivo no valores de $L$, ou seja, quanto maior a concentração e a proporção Am:Md, maior o valor $L$ obtido. Os valores de $\mathrm{L}$ neste trabalho variaram entre 62,78 e 70,00. Vergara et al. (2014) estudaram microcápsulas de betalaínas de polpa de figo da índia (Opuntia ficus-indica) usando amido modificado como agente carreador e encontraram valores de $L$ de 68,1 e 69,9 para o extrato e para a polpa, respectivamente. $\mathrm{O}$ efeito positivo da concentração de carreadores também foi observado por Caliskan e Dirim (2013) na secagem de extrato de sumagre por spray dryer utilizando maltodextrina como agente carreador, com valores de $L$ variando entre 59,15 e 75,43, semelhantes ao deste trabalho.

Quando se compara as amostras obtidas nos ensaios de secagem, pode-se observar que o aumento na concentração total de carreadores e o aumento da maldextrina produz pós com maiores valores de $L$. Isso pode ser explicado pelo fato de os carreadores serem brancos, assim produzem amostras mais claras, e os valores obtidos para $L$ são mais elevados (SOUZA et al., 2013).

A concentração e a proporção Am:Md causaram um efeito negativo no valores de $C$, ou seja, quanto maior a concentração e a proporção $\mathrm{Am}: \mathrm{Md}$, menor o valor $\mathrm{C}$ obtido. Os valores de $\mathrm{C}$ neste trabalho variaram entre 21,07 e 29,00 e representam a intensidade cromática, ou seja, quanto maior o seu valor, mais intensa a cor do produto. Vergara et al. (2014) ainda no estudo das microcápsulas de betalaínas encontraram valores de $C$ de $18,2 \mathrm{e}$ 18,7 para o extrato e para a polpa, respectivamente.
O ângulo de tonalidade cromática $h$ não apresentou diferença significativa entre as amostras estudadas.

\section{CONCLUSÃO}

A alta temperatura do processo proporcionou um alto rendimento e cápsulas com baixo teor de umidade. As amostras se apresentaram com coloração rósea e as maiores concentrações de agentes carreadores deram origem a partículas maiores, o que está relacionado ao aumento da viscosidade da mistura. O estudo da influência de agentes carreadores na secagem do extrato de beterraba por spray drying é de grande importância para facilitar e otimizar o processo de secagem. Além disso, o uso de carreadores apresenta o potencial de proteger as betalaínas, garantindo um produto estável, com baixa umidade e que poderá ser utilizado como corante natural.

\section{REFERÊNCIAS}

AOAC - ASSOCIATION OF OFFICIAL ANALYTICAL CHEMISTS. Official methods of analysis of the Association of Official Analytical Chemists. Arlington: AOAC, 1995.

BHANDARI, B. R.; SENOUSSI, A.; DUMOULIN, E. D.; LEBERT, A. Spray drying of concentrated fruit juices. Drying Technology, v.11, n.5, p.1081-1092, 1993.

CALISKAN, G., DIRIM, S. N. The effects of the different drying conditions and the amounts of maltodextrin addition during spray drying of sumac extract. Food and Bioproducts Processing, v. 9, n. 1, p. 539548, 2013.

CHETHANA, S.; CHETAN, A. N.; RAGHAVARAO, K. S. M. S. Aqueous two 
phase extraction for purification and concentration of betalains. Journal of Food Engineering, v. 81, p. 679-687, 2007.

CUCHINSK, A. S.; CAETANO, J.; DRAGUNSKI, D. C. Extração do corante de beterraba (Beta vulgaris) para utilização como indicador ácido-base. Eclética Química, v. 35, n. 4, p. 17-23, 2010.

FAZAELI, M.; EMAM-DJOMEH, Z; SHTARI, A. K.; OMID, M. Effect of spray drying conditions and feed composition on the physical properties of black mulberry juice powder. Food and Bioproducts Processing, v. 90, p. 667-675, 2012.

FERNANDES, R. V. B.; BORGES, S. V.; BOTREL, D. A. Gum Arabic/starch /maltodextrin /inulin as wall materials on the microencapsulation of rosemary essential oil. Carbohydrate Polymers, v. 101, p. 524532, 2014.

JAFARI, S.M.; ASSADPOOR, E.; HE, Y.; BHANDARI. B. Encapsulation efficiency of food flavours and oils during spray drying. Drying Technology, v.26, n.7, 816-835, 2008.

PITALUA, E.; JIMENEZ, M. VERNONCARTER, E. J.; BERISTAIN, C. I. Antioxidative activity of microcapsules with beetroot juice using gum Arabic as wall material. Food and Bioproducts Processing, v.88, p. 253-258, 2010.

RIGHETTO, A. M.; NETTO, F. M. Effect of encapsulating materials on water sorption, glass transition and stability of juice from immature acerola. International Journal of Food Properties, v. 8, p. 337-246, 2005.

SOUZA, V. B.; THOMAZINI, M.; BALIEIRO, J. C. C.; FÁVARO-TRINDADE, C. S. Effect of spray drying on the physicochemical properties and color stability of the powdered pigment obtained from vinification byproducts of the Bordo grape (Vitis labrusca). Food Bioprod Process, 2013.

http://dx.doi.org/10.1016/j.fbp.2013.11.001.

VERGARA, C.; SAAVEDRA, J.; SÁENZ, C.; GARCÍA, P.; ROBERT, P. Microencapsulation of pulp and ultrafiltered cactus pear (Opuntia ficus-indica) extracts and betanin stability during storage. Food Chemistry, v. 157, p. 246-251, 2014.

\section{AGRADECIMENTOS}

Os autores agradecem a CAPES pelo apoio financeiro. 